\title{
EFEITO DA SECAGEM POR CONVECÇÃO NA GERMINAÇÃO DE SEMENTES DE CARAMBOLA ${ }^{1}$
}

\author{
MARCIA TEREZINHA RAMOS DE OLIVEIRA², PEDRO AMORIM BERBERT ${ }^{3}$; VINICIUS DE OLIVEIRA CARLESSO ${ }^{4}$; \\ JOSÉ TARCÍSIO LIMA THIÉBAUT ${ }^{5}$; HENRIQUE DUARTE VIEIRA ${ }^{6}$; ROZIMAR DE CAMPOS PEREIRA7
}

\begin{abstract}
RESUMO - As informações disponíveis na literatura sobre o potencial fisiológico de sementes de carambola são praticamente inexistentes, embora o interesse por essa cultura venha aumentando significativamente nos últimos anos. O objetivo do trabalho foi avaliar o efeito imediato da secagem por convecção, a $38{ }^{\circ} \mathrm{C}$, sobre a germinação e o vigor das sementes. Os experimentos foram realizados tanto em germinador de câmara (entre folhas de papel) quanto em cultivo protegido (substrato comercial). Em cultivo protegido, a secagem contribuiu para o aumento da germinação de $74 \%$ (sementes recém-retiradas dos frutos) para $98 \%$. Não houve diferença significativa entre os índices de vigor estimados pelo IVE e pelo $t_{\text {médio }}$, quando se comparam plântulas originadas de sementes recém-retiradas dos frutos com aquelas obtidas a partir de sementes secadas. Pela curva de crescimento das plantas e pela variação da massa da matéria seca da parte aérea, observa-se que as plantas mais vigorosas foram aquelas originadas de sementes que passaram pelo processo de secagem.
\end{abstract}

Termos para indexação: Averrhoa carambola, germinação, índices de vigor.

\section{EFFECT OF CONVECTIVE DRYING ON THE GERMINATION OF CARAMBOLA SEEDS}

\begin{abstract}
Information on the physiological potential of carambola seeds is practically inexistent although interest in carambola production has been increasing steadily over recent years. The objective of this study was to investigate the immediate effect of convective drying at $38{ }^{\circ} \mathrm{C}$ on seed germination and vigour. Germination tests under controlled laboratory conditions were done using rolled paper towels, whereas tests in a protected environment were done using a lightweight, commercial seed-starting medium. In a protected environment, convective drying increased the percentage germination from $74 \%$ (fresh seeds) to $98 \%$ (dried seeds). Vigour, as estimated from the germination speed index and the mean time of germination, did not vary, irrespective of drying. The curves representing plant growth rate and the dry mass accumulation rate of the aerial parts of the plant, show that seeds which had been dried gave rise to more vigorous plants.
\end{abstract}

Index terms: Averrhoa carambola, germination, vigour indices.

\footnotetext{
${ }^{1}$ Submetido em 23/04/2010. Aceito para publicação em 16/07/2010. Parte da Dissertação de Mestrado do primeiro autor apresentada a UENF.

${ }^{2}$ Tecnóloga em Horticultura, M.S., UENF/CCTA/LEAG, 28013-602. Campos dos Goytacazes, maroli@uenf.br

${ }^{3}$ Eng. Agrícola, Ph.D., Prof. Associado - UENF/CCTA/LEAG, 28013602. Campos dos Goytacazes, pberbert@uenf.br

${ }^{4}$ Eng. Agr., D.S., UENF/CCTA/LEAG, 28013-602. Campos dos
}

Goytacazes, carlesso@uenf.br

${ }^{5}$ Eng. Agr., D.S., Prof. Associado - UENF/CCTA/LEAG, 28013-602. Campos dos Goytacazes, jtt1512@uenf.br

${ }^{6}$ Eng. Agr., D.S., Prof. Associado - UENF/CCTA/LFIT, 28013-602. Campos dos Goytacazes, henrique@uenf.br

${ }^{7}$ Eng. Florestal, D.S., Prof. Adjunto - UFRB, 44380.000. Cruz das Almas, rozimarcp@gmail.com 


\section{INTRODUÇÃO}

A caramboleira (Averrhoa carambola L.), frutífera exótica pertencente à família Oxalidaceae, é originária do sudoeste asiático, mas encontra-se atualmente dispersa em regiões tropicais e em áreas quentes de regiões subtropicais de todos os continentes. Foi introduzida no Brasil no início do século XVIII e é hoje cultivada em todo o país em pomares domésticos, exceto em regiões frias ou sujeitas a geadas, havendo, no entanto, poucas plantações comerciais (Crane, 1994; Donadio et al., 2001).

As sementes são oblongas e delgadas, com 6 a 13 mm de comprimento, de coloração marrom-clara, envolvidas em arilo gelatinoso. Os lóculos localizam-se nas saliências do fruto e contêm de zero a três sementes. De acordo com Donadio et al. (2001) perdem rapidamente a viabilidade depois de retiradas dos frutos. No entanto, Oliveira et al. (2009) demonstraram que sementes de carambola secadas a $38^{\circ} \mathrm{C}$, com teor de água final de $5,4 \%$ b.u., e armazenadas por 180 dias a $15{ }^{\circ} \mathrm{C}$, em embalagem impermeável, permaneceram viáveis, com germinação média de $85 \%$. Esses resultados sugerem que pode estar correta a afirmação de Ellis et al. (1985) quanto ao fato de as sementes de frutos do gênero Averrhoa apresentarem comportamento ortodoxo durante o armazenamento. Não obstante a incerteza sobre aspectos fisiológicos da germinação, observa-se que a maioria dos pomares comerciais da fruta existentes no Brasil e nos demais países é originada a partir de sementes. Uma das exceções encontra-se na Flórida (EUA), onde a enxertia, por garfagem ou borbulhia, é o principal método de propagação (Crane, 1994; Donadio et al., 2001). Bastos et al. (2009) estudaram diversos processos na tentativa de aumentar a eficiência de propagação por estaquia em caramboleira, mas não obtiveram resultados satisfatórios. As técnicas de estiolamento e incisão na base da estaca foram prejudiciais à formação de raízes adventícias e a aplicação de reguladores de crescimento não mostrou diferença significativa para o enraizamento dos tipos de estacas estudados.

Considera-se, portanto, que a carência de informações a respeito da reprodução e propagação da caramboleira é uma lacuna que precisa ser preenchida. Nesse sentido, é importante ressaltar que a maioria dos estudos sobre o efeito da secagem na qualidade fisiológica de sementes de fruteiras é realizada ao sol ou à sombra e, no caso da secagem artificial com ventilação forçada, são poucos os trabalhos realizados sob condições controladas de fluxo de ar e razão da mistura do ar de secagem. Processos não controlados de secagem podem promover queda na germinação das sementes ou mesmo plantas pouco vigorosas, resultando em baixa produtividade do pomar e grande desuniformidade de produção. Além da falta de informações sobre o préprocessamento das sementes de carambola, inexistem, também, estudos comparativos entre o teste de germinação realizado em germinador e a emergência de plântulas em cultivo protegido. Sendo assim, o objetivo do trabalho foi avaliar o efeito imediato da secagem por convecção, a $38^{\circ} \mathrm{C}$, sobre a germinação e o vigor das sementes.

\section{MATERIAL E MÉTODOS}

Este trabalho foi realizado no Laboratório de Engenharia Agrícola (LEAG) e na Unidade de Apoio à Pesquisa (UAP) do Centro de Ciências e Tecnologias Agropecuárias (CCTA) da Universidade Estadual do Norte Fluminense Darcy Ribeiro (UENF), Campos dos Goytacazes, RJ. Foram utilizadas sementes de carambola (Averrhoa carambola L.) oriundas de frutos coletados de diversas plantas de pé-franco localizadas em pomar comercial situado na localidade de Brejo Grande, pertencente ao mesmo município. A colheita foi realizada em 15/03/2006, dando origem a um lote de frutos contendo 650 carambolas. Os frutos colhidos foram cortados no sentido longitudinal e as sementes foram retiradas manualmente e transferidas para uma peneira com malha de aço, onde foram lavadas em água corrente, sendo levemente friccionadas para a retirada do arilo. Parte dessas sementes foi então utilizada para avaliação do seu potencial fisiológico antes da realização de qualquer procedimento de secagem por convecção (tratamento controle). As sementes restantes foram transferidas para um frasco hermético de vidro e armazenadas em câmara do tipo B.O.D. à temperatura de $10 \pm 1{ }^{\circ} \mathrm{C}$, de onde foram retiradas apenas na manhã do dia seguinte, 2 h antes do início do teste de secagem para que sua temperatura se igualasse à do ambiente.

O teor de água inicial das sementes foi determinado antes de se iniciar o teste de secagem, empregando-se temperatura de $130{ }^{\circ} \mathrm{C}$, por $1 \mathrm{~h}$ (Brasil, 1992). A secagem das sementes foi realizada a $38{ }^{\circ} \mathrm{C}$, com fluxo médio de ar seco de $1,0 \mathrm{~kg} \mathrm{~s}^{-1} \mathrm{~m}^{-2}$, utilizando-se secador protótipo de camada delgada, fabricado pela Indústria e Comércio de Máquinas Polidryer Ltda.; a câmara de secagem é composta por três bandejas de 0,50 x 0,62 m, construídas de malha de aço galvanizado, dispostas no secador de forma a proporcionar fluxo de ar tangencial. 
O sublote de sementes destinado à secagem foi dividido em três partes, cada parte foi colocada em uma bandeja de 0,15 x 0,15 $\mathrm{m}$ de malha de aço, num total de três bandejas. As sementes foram espalhadas no fundo perfurado dessas bandejas, formando uma camada fina de altura correspondente à espessura de uma semente. Essas três bandejas foram dispostas sobre uma das bandejas principais da câmara de secagem.

A massa inicial de sementes em cada uma das bandejas foi determinada antes do início da secagem. Sendo assim, a redução do teor de água das sementes foi monitorada por gravimetria, pesando-se o conjunto bandeja-amostra em intervalos regulares de $5 \mathrm{~min}$ nos primeiros $30 \mathrm{~min}$, de $10 \mathrm{~min}$ até os $120 \mathrm{~min}$, de $15 \mathrm{~min}$ até $180 \mathrm{~min}$ e de 30 min a partir de 180 min, utilizando-se uma balança digital Sartorius, modelo BP 4100S, com grau de acurácia de $0,01 \mathrm{~g}$.

Depois de pesadas, as bandejas retornavam ao secador, efetuando-se um rodízio de suas posições, de forma a uniformizar a secagem. Esse procedimento foi necessário, pois testes preliminares mostraram que a taxa de secagem das sementes em cada bandeja apresentava ligeira diferença, provavelmente, devido às diferenças de fluxo de ar e temperatura observados em diferentes posições na câmara de secagem. A secagem foi realizada de forma intermitente, em dois dias consecutivos, com uma única interrupção depois de 8 h e 30 mim de secagem no primeiro dia, quando o teor de água ainda encontrava-se em torno de $12 \%$. A primeira etapa do teste de secagem teve início às $09 \mathrm{~h}$ e $30 \mathrm{~min}$, com término às $18 \mathrm{~h}$. Depois de interrompida essa primeira etapa da secagem, as sementes permaneceram em repouso por 15 h e $30 \mathrm{~min}$, na condição do ambiente, antes de se iniciar a etapa final. No segundo dia do teste, a secagem foi finalmente interrompida quando o teor de água do produto encontrava-se em $7 \%$ b.u., valor próximo à condição de equilíbrio para as condições psicrométricas do ar. A segunda etapa do teste de secagem teve início às $09 \mathrm{~h}$ e 30 min, com término às $13 \mathrm{~h}$ e $30 \mathrm{~min}$.

A velocidade do ar de secagem foi medida utilizandose anemômetro de pás rotativas Airflow, Modelo AV6, posicionado na saída de ar do secador. As leituras de velocidade e temperatura foram registradas ao final de cada pesagem. A temperatura do ar de secagem foi medida utilizando-se um termômetro de mercúrio, com divisão da escala igual a $1{ }^{\circ} \mathrm{C}$, que foi colocado logo abaixo da câmara de secagem. A temperatura e umidade do ar ambiente foram medidas com aparelho digital Hygrometer, Serie
485, fabricado pela Dwyer Instruments, Inc. e registrados continuamente em termohigrógrafo Sato, do tipo Sigma II, modelo NS-Q. Pretendeu-se, com este monitoramento, avaliar as demais propriedades psicrométricas do ar de secagem, como entalpia, razão de mistura e volume específico, utilizando o programa computacional GRAPSI desenvolvido por Melo et al. (2004).

Terminada a secagem, foi avaliada a germinação das sementes em condições de laboratório e a emergência de plântulas em cultivo protegido. Por não existirem regras ou normas específicas estabelecidas para avaliação da qualidade fisiológica de sementes de carambola, arbitrouse, de acordo com informações contidas em Oliveira et al. (2009), o tempo de duração do teste, que foi de 84 dias no germinador e de 110 dias em cultivo protegido. Além disso, devido ao pequeno número de sementes por fruto (43\% contendo apenas uma semente e 33\% contendo entre duas e três sementes), o teste de germinação, em condições controladas de laboratório, foi realizado empregandose quatro repetições de 50 sementes, distribuídas em rolos de papel Germitest umedecidos com quantidade de água equivalente a 2,5 vezes a sua massa e mantidos em germinador Eletrolab, modelo 122FC, regulado aos $20{ }^{\circ} \mathrm{C}$, para o período noturno, e $30{ }^{\circ} \mathrm{C}$, para o período diurno, sob $8 \mathrm{~h}$ de fotoperíodo diário. As avaliações foram realizadas no $14^{\circ}$ dia $\left(1^{\mathrm{a}}\right.$ contagem) e as demais em intervalos regulares de 7 dias, num total de onze avaliações, sendo, portanto, a contagem final feita no $84^{\circ}$ dia. Os resultados foram expressos em porcentagem de sementes germinadas.

A avaliação da emergência de plântulas foi realizada em cultivo protegido empregando-se quatro bandejas com 96 tubetes de $115 \mathrm{~cm}^{3}$ cada, utilizando-se substrato comercial Plantmax, com semeadura à profundidade de cerca de $2 \mathrm{~cm}$, irrigando-se duas vezes ao dia. Foram feitas, adicionalmente, três aplicações de solução nutritiva padrão, com diluição 1:5 e pH de 5,5, durante a realização do experimento. Os valores médios diários de temperatura e umidade relativa do ar foram coletados na Estação Evapotranspirométrica do Laboratório de Engenharia Agrícola da UENF, localizada na área experimental da PESAGRO-RJ, em Campos dos Goytacazes, nas coordenadas de latitude $21^{\circ} 45^{\prime} \mathrm{S}$ e longitude $41^{\circ} 18^{\prime} \mathrm{W}$, e encontram-se na Figura 1.

O vigor das sementes foi avaliado pelas variáveis: índice de velocidade de emergência (IVE), tempo médio de germinação $\left(\mathrm{t}_{\text {médio }}\right)$, curva de crescimento das plantas e curva da massa de matéria seca da parte aérea em função 
da idade da planta. O IVE e o $\mathrm{t}_{\text {médio }}$ foram determinados concomitantemente ao teste de germinação, contando, a cada dia, por 110 dias, as plântulas que emergiram; foram consideradas emergidas as sementes que mostraram parte do hipocótilo acima da superfície do substrato. Tanto o IVE quanto o $t_{\text {médio }}$ foram calculados de acordo com metodologia descrita por Borghetti e Ferreira (2004). Para obtenção da curva de crescimento, as plantas foram medidas a partir da abertura dos cotilédones, a cada 5 dias, por 110 dias; o comprimento foi medido usando régua graduada em milímetros. Depois da obtenção destas medidas, as plantas foram retiradas dos tubetes, sendo posteriormente lavadas e secadas levemente com papel toalha. Separou-se a raiz da parte aérea, cortando a planta, com uma tesoura, na região do coleto.

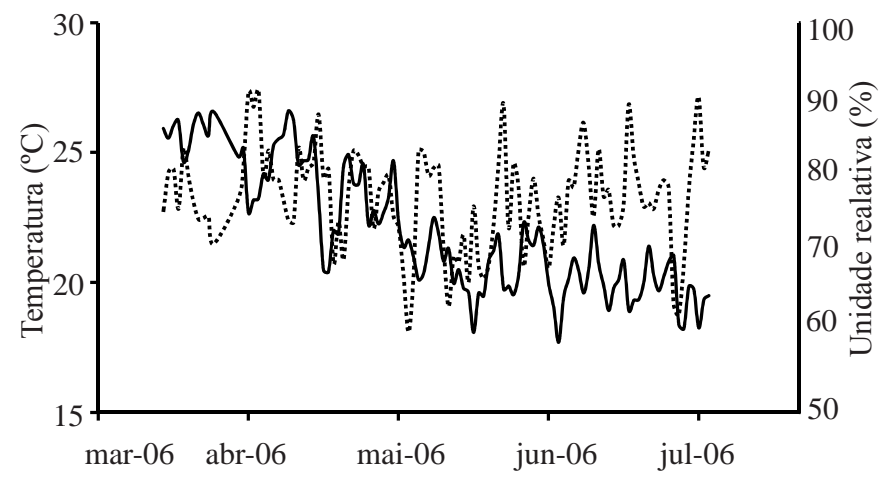

FIGURA 1. Valores médios diários de temperatura (—) e umidade relativa ( -...-) coletados na Estação Evapotranspirométrica do Laboratório de Engenharia Agrícola da UENF, durante experimento de emergência de plântulas de carambololeira em cultivo protegido.

A parteaérea, depois deseparadadaraiz, foi seccionada e acondicionada individualmente em recipientes de alumínio com massa previamente determinada e pesados usando balança Sartorius, modelo BL 210S (0,0001 g) para determinar a massa da matéria úmida. As amostras foram transferidas para estufa com circulação forçada de ar, a $103 \pm 1{ }^{\circ} \mathrm{C}$ por $24 \mathrm{~h}$, para a determinação da massa de matéria seca, de acordo com as especificações da Norma S358.2 proposta por ASAE (2000).
A análise estatística dos dados foi feita empregandose o método de Amostragem Simples ao Acaso (Cochran, 1977). Nesse método, cada semente representa uma unidade experimental. As proporções de germinação e vigor foram analisadas e comparadas por meio de intervalos de confiança, para o nível de significância de 5\%. As amostras foram dimensionadas considerando $\alpha=5 \%$ e $d=5 \%$ da média amostral. Desta forma, os intervalos disjuntos caracterizam diferentes proporções das características germinação e vigor, ou seja, nas figuras mostrando os resultados da qualidade fisiológica obtidos pelo método da amostragem, a ocorrência de qualquer nível de superposição das barras horizontais que representam os intervalos de confiança para proporção de germinação e vigor, revela que não há diferença significativa entre os tratamentos.

As equações que representam tanto a curva de crescimento de plantas quanto a curva de variação da massa de matéria seca da parte aérea das plantas, foram obtidas por regressão linear, com utilização de variável binária $s$, que indica se houve ou não secagem das sementes, ou seja, $s=1$ ou $s=0$, respectivamente.

\section{RESULTADOS E DISCUSSÃO}

Na Tabela 1 são apresentados os valores médios e os respectivos desvios-padrão das variáveis associadas ao ar ambiente e de secagem, as condições iniciais e finais das sementes, e o tempo de secagem nas duas etapas de realização do teste. Observa-se que, na primeira etapa foram necessárias 8 h e 30 min de secagem para reduzir o teor de água das sementes de cerca de $48 \%$ para $12 \%$ b.u., ou seja, a taxa de secagem média foi de 4,2 pontos percentuais de água retirados por hora de secagem. Durante o período de repouso de 15 h e 30 min as condições médias de temperatura e umidade relativa do ambiente foram $28,8 \pm 0,7$ ${ }^{\circ} \mathrm{C}$ e $60,3 \pm 2,8 \%$. A razão da mistura, para essa condição, foi $0,015 \mathrm{~kg}$ de vapor d'água por kg de ar seco. Portanto, verifica-se que houve secagem parcial, com redução de 1,6 pontos percentuais de teor de água, durante o período de repouso das sementes nas condições do ambiente.

Apresentam-se, na Figura 2, os intervalos da proporção de germinação de sementes de carambola para os testes realizados em condições de laboratório; os intervalos da proporção de germinação em cultivo protegido encontramse na Figura 3. O percentual médio de germinação das sementes recém retiradas dos frutos e colocadas em tubetes contendo substrato comercial Plantmax foi de $74 \%$. O valor correspondente para sementes colocadas 
para germinar imediatamente depois da secagem foi de $98 \%$. É importante ressaltar que o valor de $20 \%$ de germinação obtido para sementes imediatamente depois da secagem e colocadas para germinar entre rolos de papel Germitest, não deve ser considerado na avaliação do efeito da secagem, uma vez que, para essa situação, o teste foi interrompido na metade da duração da contagem, ou seja, aos 42 dias, quando o substrato e as sementes encontravam-se totalmente contaminados por microorganismos. Na análise das diferenças, é necessário destacar, também, que o tempo de duração dos testes não foi o mesmo, ou seja, de 84 dias, em laboratório, e de 110 dias, em cultivo protegido. Além disso, a primeira semente emergida, em cultivo protegido, foi observada aos 25 dias, ao passo que nas condições de laboratório, esse período variou de 14 a 21 dias.

TABELA 1. Data de realização dos testes experimentais de secagem, condições médias do ar e das sementes de carambola e tempo de secagem.

Condições do ar e das sementes

Primeira etapa da secagem

$(16 / 03 / 2006)$
Segunda etapa da secagem

$(17 / 03 / 2006)$

\begin{tabular}{ccc}
\hline Ar ambiente: & & \\
\hline Temperatura, ${ }^{\circ} \mathrm{C}$ & $31,0 \pm 0,8$ & $30,7 \pm 0,3$ \\
Razão da mistura, $\mathrm{kg} \mathrm{kg}^{-1}$ & $0,018 \pm 0,002$ & $0,017 \pm 0,001$ \\
\hline Ar de secagem: & $38,5 \pm 1,1$ & $37,1 \pm 0,8$ \\
\hline Temperatura, ${ }^{\circ} \mathrm{C}$ & $0,970 \pm 0,028$ & $1,051 \pm 0,040$ \\
\hline Fluxo de ar seco, $\mathrm{kg} \mathrm{s}^{-1} \mathrm{~m}^{-2}$ & & 30,7 \\
\hline Condições iniciais das sementes: & 31,8 & $10,6 \pm 2,3$ \\
\hline Temperatura, ${ }^{\circ} \mathrm{C}$ & $47,9 \pm 0,3$ & 37,1 \\
Teor de água, $\%$ b.u. & & $6,9 \pm 0,7$ \\
\hline Condições finais das sementes: & 38,0 & \\
\hline Temperatura, ${ }^{\circ} \mathrm{C}$ & $12,2 \pm 2,5$ & 4,0 \\
Teor de água, $\%$ b.u. & & 8,5 \\
\hline Tempo de secagem:
\end{tabular}

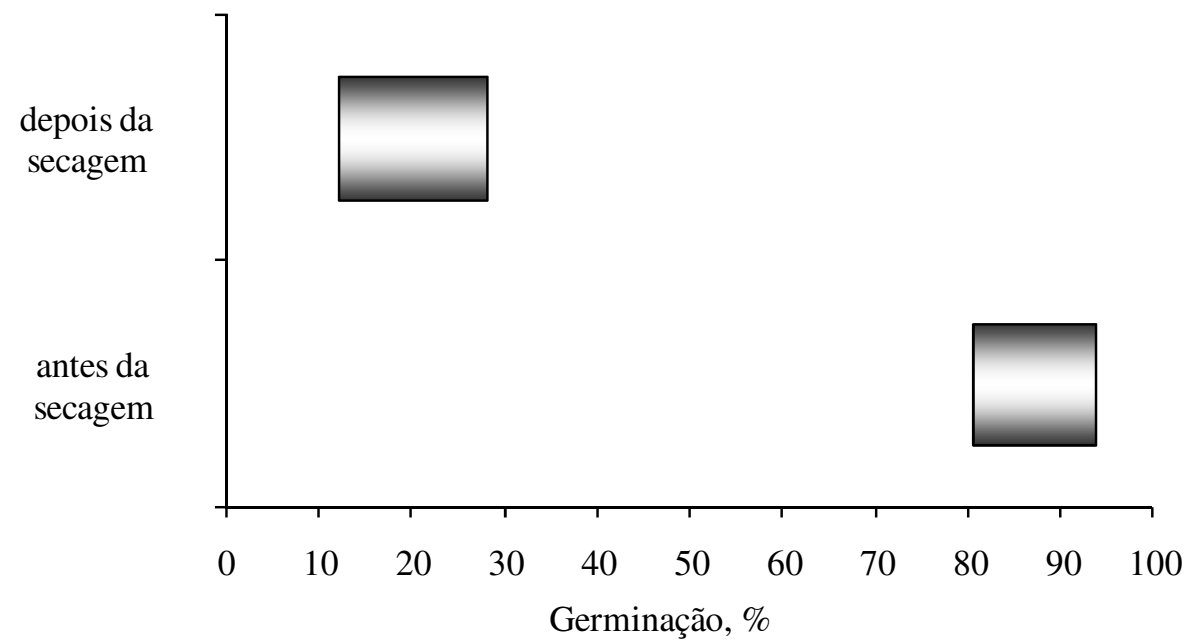

FIGURA 2. Intervalos de confiança, aos $95 \%$ de probabilidade, para proporção de germinação de sementes de carambola em condições de laboratório, antes e logo depois da secagem. 


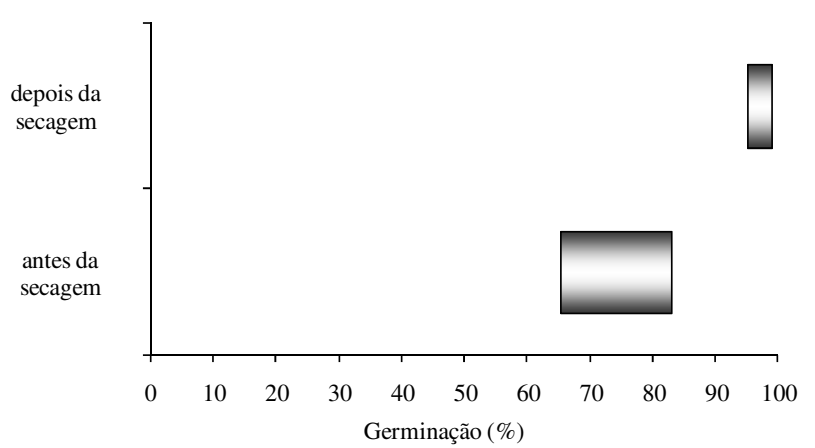

FIGURA 3. Intervalos de confiança, aos $95 \%$ de probabilidade, para proporção de germinação de sementes de carambola em cultivo protegido, antes e logo depois da secagem.

De qualquer forma, observa-se que a secagem em $38{ }^{\circ} \mathrm{C}$ contribuiu para o aumento do percentual de germinação em cultivo protegido. No entanto, a comparação entre as duas condições, laboratório e cultivo protegido, ficou comprometida devido à deterioração das sementes secadas e colocadas para germinar entre rolos de papel Germitest. Porém, para sementes que não foram secadas, ou seja, com teor inicial de água de $48 \%$ b.u., a germinação entre rolos de papel ( 80 a $93 \%$ ) não diferiu significativamente daquela observada em substrato comercial, em cultivo protegido (65 a $82 \%$ ), conforme ilustram as Figuras 2 e 3. Oliveira et al. (2009) avaliaram os efeitos da temperatura do ar de secagem $\left(30,34\right.$ e $\left.38^{\circ} \mathrm{C}\right)$ e do período de armazenamento aos $15{ }^{\circ} \mathrm{C}(45,60,90,180$ e 270 dias $)$ sobre a qualidade fisiológica de sementes de carambola, empregando germinador de câmara e usando papel como substrato nos testes de germinação, e verificaram que não houve efeito imediato da secagem aos $38{ }^{\circ} \mathrm{C}$ no percentual de germinação das sementes; observaram, no entanto, que o efeito da secagem foi latente, quando se verificou melhora significativa no percentual de germinação, de 65 para $85 \%$, ao final de 180 dias de armazenamento.'

Apresentam-se, nas Figuras 4 e 5, os intervalos de confiança para o IVE e $t_{\text {médio }}$, respectivamente, em cultivo protegido, para sementes de carambola antes e imediatamente depois da secagem. Observa-se, nessas figuras, que a secagem aos $38{ }^{\circ} \mathrm{C}$ não teve efeito significativo sobre o IVE e $t_{\text {médio }}$.

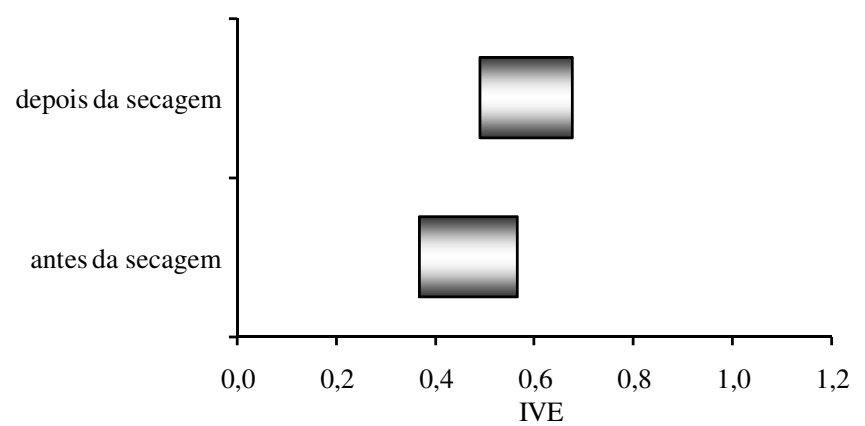

FIGURA 4. Intervalos de confiança, aos $95 \%$ de probabilidade, para o IVE de sementes de carambola, antes e logo depois da secagem, em cultivo protegido.

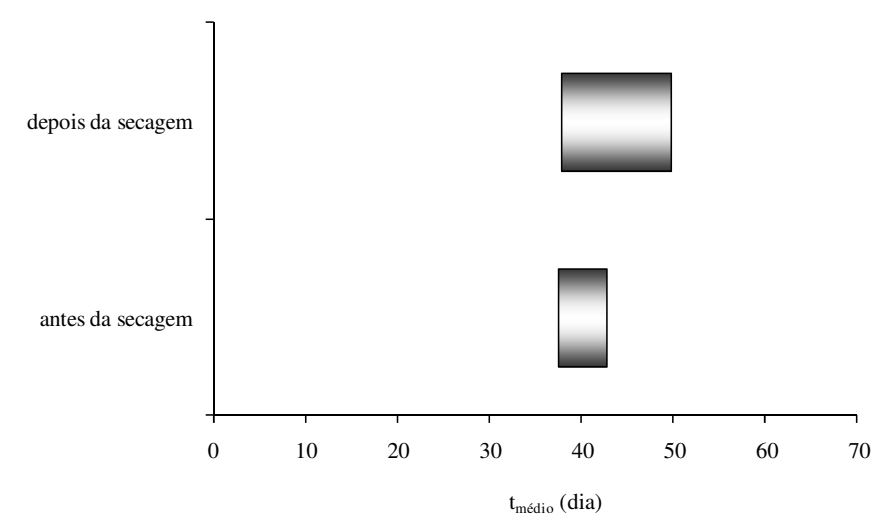

FIGURA 5. Intervalos de confiança, aos $95 \%$ de probabilidade, para $0 t_{\text {médio }}$ de sementes de carambola, antes e logo depois da secagem, em cultivo protegido.

As curvas de crescimento das plantas, para sementes submetidas ou não à secagem, são mostradas na Figura 6. A amostra, para cada tempo, foi representativa de população infinita, para nível de significância de $5 \%$ e desvio de $5 \%$ da média amostral. A equação de regressão, Equação (1), que representa a curva de crescimento de plantas originadas de sementes submetidas ou não a secagem, obtida com a utilização de variável binária, para a análise de identidade de modelo, foi significativa em $1 \%$ de probabilidade, considerando o modelo polinomial de segundo grau, analisando a altura em função do tempo. Na Equação (1), $\hat{h}$ representa a altura estimada da planta, em cm; $s$ é a variável binária que indica se houve ou não secagem das sementes, ou seja, $s=1$ ou $s=0$, respectivamente. O coeficiente de determinação da Equação (1), que foi obtida empregando- 
se todos os valores observados de altura, para cada idade da planta, e não a sua média, foi de $72 \%$.

$$
\hat{\mathrm{h}}=2,01426+0,11705 \mathrm{t}-0,00075 \mathrm{t}^{2}+0,02435 \text { s.t }(1)
$$

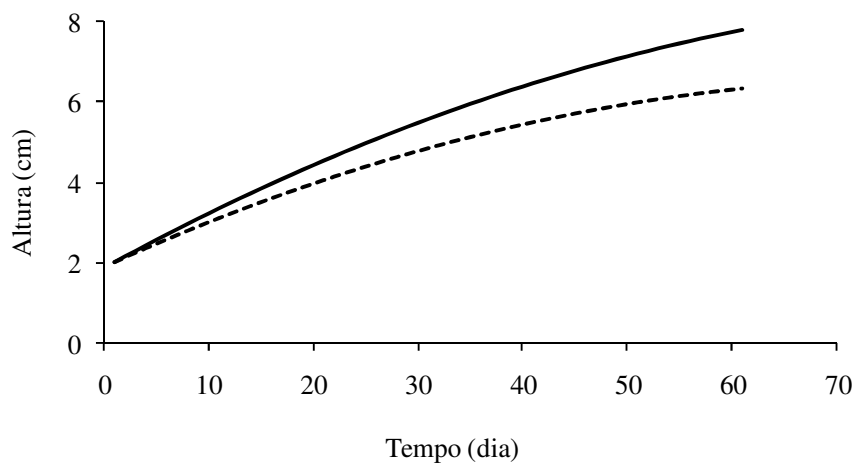

FIGURA 6. Curva de crescimento das plantas de caramboleira em função da idade. ----, plantas originadas de sementes recém retiradas dos frutos, sem secar, com teor de água de $48 \%$ b.u. ( $\left(\hat{\mathbf{h}}=-0,00075 \mathrm{t}^{2 * *}\right.$ $\left.+0,11705 t^{* *}+2,01426\right) ;-$, plantas originadas de sementes logo depois da secagem a $38{ }^{\circ} \mathrm{C}$, com teor de água de $7 \%$ b.u. $\left(\hat{\mathbf{h}}=-0,00075 t^{2 *}+0,14140 t^{* *}\right.$ $+2,01426)$. ** significativo em $1 \%$ de probabilidade pelo teste $\mathbf{t} ; \hat{\mathbf{h}}=$ altura da planta de caramboleira $(\mathrm{cm}) ; \mathrm{t}=$ idade da planta (dia).

$\mathrm{Na}$ comparação dos coeficientes de regressão, o intercepto foi o mesmo para ambas situações, não diferindo, portanto, aos 5\% de probabilidade. O mesmo não ocorreu com a declividade das curvas, ou seja, o crescimento das plantas obtidas de sementes que foram secadas ( $s=1$, na Equação 1) foi significativamente superior ao daquelas obtidas de sementes que não o foram ( $s=0$, na Equação 1).

O desempenho das plantas, em termos de vigor, foi avaliado também pela massa da matéria seca da parte aérea ao final de 110 dias em cultivo protegido. As curvas representativas da massa da matéria seca da parte aérea das plantas, em função da sua idade, para sementes submetidas ou não à secagem, são mostradas na Figura 7. Nas Figuras 6 e 7, o tempo representa o número de dias após a abertura dos cotilédones. A equação de regressão, Equação (2), para a massa da matéria seca da parte aérea de plantas oriundas de sementes submetidas ou não a secagem, e também obtidas com a utilização de variável binária, para a análise de identidade de modelo, foi significativa em 5\% de probabilidade, considerando o modelo linear de $1^{\circ}$ grau, da massa seca $(\mathrm{m})$ da parte aérea das plantas em função da idade. Na Equação (2), $\hat{\mathrm{m}}$ representa a massa estimada, em g; s é a variável binária que indica se houve ou não secagem das sementes. O coeficiente de determinação da Equação (2), que foi obtida empregando-se todos os valores observados de massa, para cada idade da planta, e não a sua média, foi de $67 \%$.

$$
\hat{\mathrm{m}}=-0,09083+0,00224 \mathrm{t}+0,00019 \text { s.t }(2)
$$

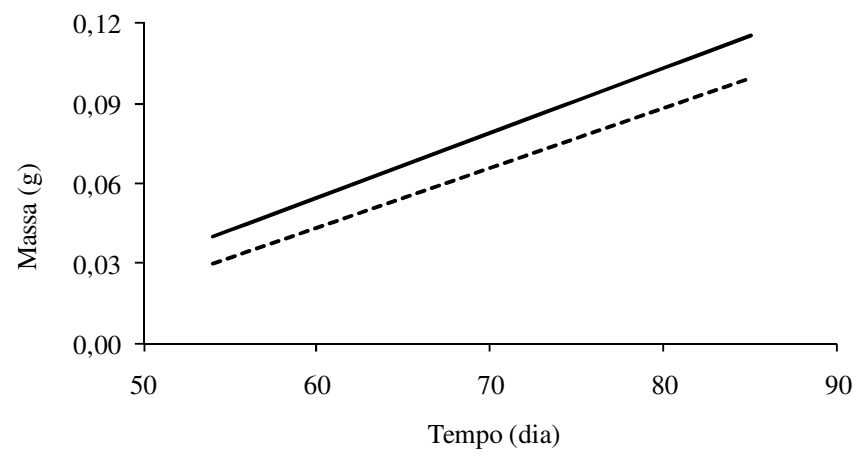

FIGURA 7. Variação da massa de matéria seca da parte aérea de plantas de caramboleira em função da idade. ----, plantas originadas de sementes recém-retiradas dos frutos, sem secar, com teor de água de $48 \%$ b.u. $\left(\hat{\mathrm{m}}=-0,09083+0,002248 \mathrm{t}^{*}\right) ;-$, plantas originadas de sementes logo depois da secagem a $38{ }^{\circ} \mathrm{C}$, com teor de água de 7\% b.u. $(\hat{\mathrm{m}}=-0,09083+0,002424 \mathrm{t} *)$ * significativo aos $5 \%$ de probabilidade pelo teste $\mathbf{t} ; \hat{\mathrm{m}}=$ massa de matéria seca da parte aérea da planta de caramboleira (g); $t=$ idade da planta (dia).

\section{CONCLUSÕES}

Para sementes recém-retiradas dos frutos, não houve diferença entre a germinação obtida em laboratório e a emergência de plântulas em substrato comercial em cultivo protegido. No entanto, em cultivo protegido, a secagem a $38{ }^{\circ} \mathrm{C}$ contribuiu para o aumento da germinação. Pela curva de crescimento das plantas e pela variação da massa da matéria seca da parte aérea, observa que plantas mais vigorosas são originadas de sementes que passa pelo processo de secagem. 


\section{AGRADECIMENTOS}

Os autores agradecem o apoio financeiro oferecido pelas seguintes instituições: CAPES, CNPq, FAPERJ, FINEP e International Foundation for Science (IFS).

\section{REFERÊNCIAS}

AMERICAN SOCIETY OF AGRICULTURAL ENGINEERS. ASAE Standards. ASAE S358.2: Moisture Measurement - Forages. St. Joseph, 2000. 565p.

BASTOS, D.C.; SCARPARE FILHO, J.A.; LIBARDI, M.N.; PIO, R. Estiolamento, incisão na base da estaca e uso do ácido indolbutírico na propagação da caramboleira por estacas lenhosas. Ciência e Agrotecnologia, v.33, n.1, p.313-318, 2009.

BORGHETTI, F.; FERREIRA, A.G. Interpretação de resultados de germinação. In: FERREIRA, A.G.; BORGHETTI, F. (Ed.) Germinação: do básico ao aplicado. Porto Alegre: Artmed, 2004. p.209-222.

BRASIL. Ministério da Agricultura e Reforma Agrária. Secretaria Nacional de Defesa Agropecuária. Departamento Nacional de Produção Vegetal. Coordenação de Laboratório Vegetal. Regras para Análise de Sementes. Brasília, DF, 1992. 365p.
COCHRAN, W.G. Sampling techniques. New York: John Wiley \& Sons, Inc., 1977. 448p.

CRANE, J.H. The carambola. Fact Sheet HS-12. Gainesville: University of Florida, 1994. 6p.

DONADIO, L.C.; SILVA, J.A.A.; ARAÚJO, P.S.R.; PRADO, R.M. Caramboleira (Averrhoa carambola L.). Jaboticabal: Sociedade Brasileira de Fruticultura, 2001. 81p.

ELLIS, R.H.; HONG, T.D.; ROBERTS, E.H. Oxalidaceae. Handbook of Seed Technology for Genebanks. In: ELLIS, R.H.; HONG, T.D.; ROBERTS, E.H. (Ed.) Compendium of specific germination information and test recommendations. Rome: International Board for Plant Genetic Resources, 1985. Chapter 52, v.2.

MELO, E.C.; LOPES, D.C.; CORRÊA, P.C. GRAPSI Programa computacional para o cálculo das propriedades psicrométricas do ar. Engenharia na Agricultura, v.12, n.2, p.154-162, 2004.

OLIVEIRA, M.T.R.; BERBERT, P.A.; PEREIRA, R.C.; VIEIRA, H.D.; THIÉBAUT, J.T.L.; CARLESSO, V.O. Qualidade fisiológica e potencial de armazenamento de sementes de carambola. Revista Brasileira de Sementes, v.31, n.2, p.236-244, 2009. 